\title{
"A Study to Assess the Effectiveness of Group Therapy on Psychological Wellbeing among Alcohol Dependents At Selected De-Addiction Centre, Puducherry".
}

\author{
Mr.S.Sugumar ${ }^{1}$, Mrs.S.Prabavathy ${ }^{2}$, Dr. Renuka $\mathrm{K}^{3}$
}

\begin{abstract}
Aims:

To evaluate the effectiveness of group therapy among alcohol dependents at selected de-addiction centre, Puducherry.

Materials and Methods: Pre-experimental research design with one group pre-test and post-test was adopted. Forty samples of alcohol dependents (male) were selected from Bharatha Matha De-Addiction Centre, Ariyankuppam, Puducherry. Samples were selected by using purposive sampling technique. Forty samples were divided into four groups, each group consisting of 10 members. Group therapy was administered twice a week for 2 hours for 4 weeks. The data were collected by using structured interview schedule. The reliability of the tool was $r=0.893$, and it was analyzed in terms of descriptive and inferential statistics by using Wilcoxon signed rank test and Chi-square test.
\end{abstract}

Results: This study result showed that pre-test median score was 22.5, post-test median score was 73.5, Wilcoxon test value is 5.512 and p-value is 0.001 . Thus, the group therapy was effective on psychological wellbeing among alcohol dependents. There is a significant association between the selected demographic variables such as age in years, duration of addiction in years and amount of alcohol intake per day with the psychological wellbeing of alcohol dependents at $p<0.001$.

Conclusion: This study findings reveals that the group therapy is effective to bring about changes in the level of psychological wellbeing among alcohol dependents. The level of psychological wellbeing has improved from poor- to moderate-level to good-level of psychological wellbeing.

Keywords: Group Therapy, Psychological Wellbeing and Alcohol dependents.

M,Sc (Mental Health Nursing) ., \& Guide, Dept of MHN, KGNC ${ }^{2}$, \& Principal of KGNC ${ }^{3}$.

\section{Introduction}

Alcoholism is one of the major medical and public health problems all over the world. It is now generally recognized that alcohol is one of the major social, economic problems confronting the society. The World Health Organization (2006) estimates that there are about 2 billion people worldwide who consume alcoholic beverages and 76.3 million with diagnosable alcohol use disorders. Alcohol consumption has health and social consequence via intoxication (drunkenness), alcohol dependence and other biochemical effects of alcohol.Alcoholism is considered as a family disease and not just something that affects an individual. ${ }^{1}$ Psychological wellbeing in terms of internal experience of the respondents and their own perception of their lives. We focused both on momentary moods and long-term states of their mental wellbeing. Group therapy is a form of psycho-social treatment where a small group of patients meet regularly to talk, interact and discuss problems with each other and with the group leader. Group therapy for alcohol abuse has long been a proven and effective method, and it should definitely be considered as a form of treatment. ${ }^{2}$

\section{Need for the study}

Alcohol use is an important public health problem, especially in developing countries like India. It is estimated that $20-40 \%$ of men between 15 and 60 years of age consume alcohol regularly. ${ }^{3}$ In 2012, worldwide 3.3 million people die every year due to harmful use of alcohol, representing $5.9 \%$ of all deaths. In India (May 2014), WHO found that $32 \%$ of men and fewer than $11 \%$ of women over the age of 15 drink alcohol. ${ }^{4}$

In Puducherry, as per Indian Journal of Psychiatry dated March 20, 2015, around 30-50\% of male suicides were under the influence of alcohol and many wives have been driven to suicide by their alcoholic husbands. Alcoholism is a major public health problem in Puducherry. studies have found that group therapy focusing on social skills, coping styles education about the addiction, interpersonal dynamics and the treatment of self deficits is useful in achieving and retaining recovery from alcohol. Group therapy allows to learn from the experiences of others with similar problems and also allow to better understand how people vary from one's view about the world and interact with others ${ }^{5}$. 
"A study to assess the effectiveness of group therapy on psychological wellbeing among alcohol ..

\section{III. statement of the problem}

A study to assess the effectiveness of group therapy on psychological wellbeing among alcohol dependents at selected de-addiction centre, Puducherry.

\section{Objectives of the study}

- To assess the level of psychological wellbeing among alcohol dependents.

- To evaluate the effectiveness of group therapy on psychological wellbeing among alcohol dependents.

- To associate the level of psychological wellbeing among alcohol dependents with the selected demographic variables.

\section{Operational definitions}

Assess: Refers to the activity that decides the level of psychological wellbeing among alcohol dependents measured by using Structured Interview Schedule.

Effectiveness: Effectiveness refers to the significant improvement in the level of psychological wellbeing achieved by group therapy that is measured by Structured Interview Schedule.

Psychological wellbeing: Subjective feeling of mental wellness.

Group therapy: It is a psychotherapy which helps the alcohol dependents in the promotion of psychological wellbeing.

Alcohol dependents: Person who is physically and psychologically dependent on drinking alcohol and seeking treatment in addiction centre.

Hypotheses: $\mathrm{H}_{1}$ : There is a difference in the level of psychological wellbeing before and after group therapy among alcohol dependents.

$\mathrm{H}_{2}$ : There is an association between the level of psychological wellbeing among alcohol dependents and the selected demographic variables.

\section{Research Methodology}

In this study, the methodology includes the research approach, approach design, the setting of the study, population, sample and sampling technique, development of the tool, data collection and plan for analysis.

\section{Research approach}

The research approach used for the study was quantitative approach was considered as a appropriate.

Research design

The research design used for the study was Pre Experimental One Group Pre-and Post Test design.

Variables

Independent variable Group therapy

Dependent variable Psychological wellbeing

Setting of the study

Present study was conducted at Bharatha Matha De-addiction Centre, Ariyankuppam, Puducherry. The target population of the study is alcohol dependents aged between 20 and 60 years in Bharatha Matha De-addiction Centre, Ariyankuppam, Puducherry.

Sample and sampling technique Purposive sampling technique was adopted.

Sample size The sample size for the study is 40 (alcohol dependents aged between 20 and 60 years in Bharatha Matha De-addiction Centre, Ariyankuppam, Puducherry).

\section{Criteria for sample selection}

Inclusion criteria

$>$ Alcohol dependents who are willing to participate.

$>$ Alcohol dependents who have recovered from withdrawal symptoms.

$>$ Alcohol dependents who have poor and moderate psychological wellbeing.

\section{Exclusion criteria}

$>$ Alcohol dependents who have aggressive behaviour.

$>$ Alcohol dependents who have good psychological wellbeing.

Description of tool: part I Demographic variables (age, religion, educational status, occupation, monthly income, marital status, type of family, type of admission, number of children, duration of addiction in alcohol, frequency of intake of alcohol, influenced by whom, Amount of alcohol taken per day, duration of stay in deaddiction centre).

Part II:The Structured Interview Schedule was used to assess the level of psychological wellbeing. It consists of 50 items that assess the level of psychological wellbeing questionnaire used for alcohol dependents assessment. 


\section{Data Analysis And Interpretation}

The analysis and interpretation of data of this study are based on data collected through interviews by using Modified Structured Interview Schedule. The results are computed using descriptive and inferential statistics.

\section{Section-A}

Table 3.1 Distribution of pre-test and post-test level of psychological wellbeing among alcohol dependents

\begin{tabular}{|l|l|l|l|l|}
\hline Level of psychological wellbeing & Pre-test & Post-test & $\begin{array}{l}\text { Percentage } \\
(\%)\end{array}$ \\
\cline { 2 - 5 } & $\begin{array}{l}\text { Frequency } \\
(\mathbf{n})\end{array}$ & $\begin{array}{l}\text { Percentage } \\
(\%)\end{array}$ & $\begin{array}{l}\text { Frequency } \\
(\mathbf{n})\end{array}$ & 0.00 \\
\hline Good & 0 & 0 & 40 & 00 \\
\hline Moderate & 25 & 62.5 & 00 & 00 \\
\hline Poor & 15 & 37.5 & 00 & 100 \\
\hline TOTAL & 40 & 100 & 40 & 00 \\
\hline
\end{tabular}

Table 3.1 shows Distribution of pre-test and post-test level of psychological wellbeing among alcohol dependents. $25(62.5 \%)$ of them had moderate psychological wellbeing, 15(37.5\%) of them had poor psychological wellbeing. After group therapy administered 40 (100\%) of them has been promoted to good psychological wellbeing.

\section{Conclusion}

This study revealed that median level of psychological wellbeing in pre test $22.5 \%$, after administration of group therapy median level of psychological wellbeing in post test $73.5 \%$. Thus, this study proves that group therapy was effective in promotion of psychological wellbeing among alcohol dependents.

\section{References}

[1]. Vyas JN. Ahuja N. Textbook of postgraduate psychiatry: Jaypee Brothers. 2nd edition. 2007.p.187-91

[2]. Ahuja N. A short textbook of psychiatry: Jaypee Brothers $6^{\text {th }}$ edition.2006. p.213-17

[3]. Fortinash KM. Holody Worret PA. Psychiatric mental health nursing: Mosby publications. 3rd edition.2004. p.117-18

[4]. Mahajan BK. Methods in biostatistics: Jaypee Publication.6th edition.2006. p.337-39

[5]. Goodheart CD. Kazdin A.Sternberg RJ. Evidence based psychotherapy: Sheridan Books publication.1st edition. 2006.p.221-23 